\title{
Holistic approaches to e-learning accessibility
}

\author{
Lawrie Phipps ${ }^{\mathrm{a}}$ and Brian Kelly*b \\ afISC TechDis Service; ${ }^{\mathrm{b}} U K O L N$, UK
}

\begin{abstract}
The importance of accessibility to digital e-learning resources is widely acknowledged. The World Wide Web Consortium Web Accessibility Initiative has played a leading role in promoting the importance of accessibility and developing guidelines that can help when developing accessible web resources. The accessibility of e-learning resources provides additional challenges. While it is important to consider the technical and resource related aspects of e-learning when designing and developing resources for students with disabilities, there is a need to consider pedagogic and contextual issues as well. A holistic framework is therefore proposed and described, which in addition to accessibility issues takes into account learner needs, learning outcomes, local factors, infrastructure, usability and quality assurance. The practical application and implementation of this framework is discussed and illustrated through the use of examples and case studies.
\end{abstract}

\section{Introduction}

The importance of universal accessibility to web resources is widely acknowledged (Witt \& McDermott, 2002; Kelly et al., 2005a). The Web Accessibility Initiative (WAI) of the World Wide Web Consortium (WC3) has developed guidelines that help to ensure web resources can be accessed by people with disabilities. With the Web providing the main delivery channel for e-learning resources, it would appear that adhering to the WAI guidelines should be a requirement for e-learning development. However, we put the case for a wider perspective that recognises the limitations of implementing the WAI guidelines.

\section{Challenges in implementing the WAI WCAG guidelines}

The WC3 (the body responsible for the coordination of developments to web standards) established the WAI with a remit to lead the Web to its full potential with a

\footnotetext{
* Corresponding author. UKOLN, University of Bath, Bath BA2 7AY, UK.

Email: B.Kelly@ukoln.ac.uk
} 
particular reference to promoting a high degree of accessibility for people with disabilities. The WAI has successfully raised awareness of the importance of web accessibility and developed guidelines that help to ensure web resources are accessible, with the Web Content Accessibility Guidelines (WCAG) (WAI, 1999, 2004) being of particular relevance to developers of web resources.

In 2001 the UK Government introduced the Special Educational Needs and Disability Act (HMSO, 2001), bringing the previously excluded elements of the education sector within the remit of existing anti-discrimination legislation. In the same year the Joint Information Systems Committee established the TechDis service with a remit for all aspects of technology and disability within education. Since 2001 the service has been working with other intermediaries to try and understand the ramifications of the legislation for, among other things, e-learning.

An excellent overview of the legislation highlighting many of the issues that would be affected by the legislation is given in Willder (2002). However, she concludes that until the legislation is tested it will be difficult to draw conclusions. Sloan (2002) suggests that there is little doubt that e-learning will be within the scope of UK legislation:

[...] it can be seen that there is likely to be a duty on higher and further education institutions to ensure that their online teaching resources and VLEs are provided in a form accessible to disabled students. Further, institutions will be expected to make 'reasonable adjustments' to overcome these problems and are unlikely to be able to justify continuing discrimination.

Over a period of four years the authors have been working together with academic staff and individuals working in the policy area to better understand how standards and guidelines fit together with UK legislation, and how that then transposes onto the learning experience of a disabled student in the United Kingdom. In working with learning technologists, disability staff and lecturers, the authors have come to some interesting conclusions and challenges to those who are working in the field of accessibility. For example, Kelly et al. (2005b) describe some of the experiences of staff involved in e-learning attempting to map their work onto WCAG guidelines. They conclude that while the WCAG guidelines have a very important role to play in the creation of more generic web-based materials, it is difficult to relate the same approach to a rich e-learning experience that is accessible to all students. They reflect that the application of guidelines to individual objects can create proble

\section{A holistic approach}

As a result of the increasing emphasis on accessibility within higher and further education, accessibility has generally become synonymous with web accessibility or the accessibility of e-learning. However, to staff who are just starting out in educational development or using technology in a very iterative way with students, the application of accessibility-related standards and guidelines can be at best a discouragement or at worst damaging, preventing staff from exploring the potential of elearning (Kelly et al., 2003a, b). 
This approach to accessibility (focusing solely on accessibility guidelines) also ignores a major facet of the educational experience: it is holistic. Students attend an institution and partake of a range of facilities and activities-some they will not relate to, others they will. Because a disabled student cannot access one type of assessment that happens to be delivered via a web browser, it does not mean they cannot instead do an oral examination in a one-to-one situation. The current accessibility paradigm places emphasis on total online access or, if materials cannot be made accessible, then providing an equivalent online experience. This can be damaging to the educational experience of attending an institution, ignoring the fact that institutions and their staff deploy a range of learning methods, some of which will suit all students and others will not. Therefore, in our opinion, the only way to judge accessibility of e-learning within an institution is to assess it holistically and not to judge it by a single method of delivery.

We propose a holistic approach to supporting the development of e-learning resources that addresses the following issues:

- usability;

- making learning accessible;

- making courses accessible; and

- adapting to individual, local political and cultural factors.

\section{Usability issues}

The Disability Rights Commission (2004) report highlighted the importance of website usability for people with disabilities. The report pointed out that:

$45 \%$ of [the total 585 accessibility and usability] problems were not a violation of any (WAI WCAG) Checkpoint and could therefore have been present on any WAI-conformant site regardless of rating.

This point illustrates a limitation of the WAI WCAG guidelines. It should be selfevident that quality e-learning web resources should be usable and not just accessible. However the strong emphasis given to accessibility, especially with concerns sometimes expressed that failure to comply with W3C WAI WCAG guidelines could lead to legal action, can lead to failure to give equal weight to usability issues.

Although it might appear desirable to include usability alongside accessibility, there is a need to be aware of potential conflicts. This may be partly due to poor support for web standards in browsers. In addition users may express preferences for e-learning resources, which have conflict with accessibility guidelines. This can be illustrated by focusing on the proprietary Flash format, which is widely used for the development of interactive e-learning resources and online games. Despite being highly visual, Flash resources can be accessible. The Royal National Institute for the Blind (RNIB), for example, has encouraged the development of accessible Flash resources. The RNIB (undated) also provide advice on the development of accessible Flash resources. Although resources such as the RNIB 'Blind Date' game may be usable and accessible, they would not appear to comply with the WAI WCAG guidelines as 
they make use of a proprietary file format, something that the guidelines advise against.

\section{Accessible e-learning or accessible learning?}

In adopting a holistic approach to accessible e-learning we argue that there is a need to provide accessible learning experiences, and not necessarily an accessible e-learning experience. This approach has parallels with the concept of blended learning rather than the more limited e-learning approach. As an example, consider an e-learning environment that provides a highly interactive three-dimensional visualisation of a molecule. Such an environment is likely to be very difficult to make accessible to a visually impaired student or a student with impaired motor skills. Rather than seeking to develop an accessible version of such an environment (which, if possible to do, may prove costly, without any guarantee that the accessible equivalent will be usable by the student with disabilities), we argue that the teacher should consider the learning experience provided by the e-learning resources and seek to develop an alternative that provides an equivalent learning experience. In many cases it should be possible to find an acceptable equivalent learning experience, such as the resources used prior to the development of the e-learning resource (e.g. a physical representation of a molecule).

This approach may also be used when a real-world learning experience is not accessible. For example, consider a field course for a geography student, which requires climbing a mountain or other terrain unsuited for a student in a wheelchair or with similar physical disabilities (this may include an overweight student or a heavy smoker who finds physical exertions difficult). A blinkered approach may seek to make the mountain accessible by using expensive all-terrain vehicles, building appropriate paths and ramps at key sites or, in the worst-case scenario, cancelling the field trip for all students. A holistic approach however, allows the teacher to identify the learning experiences (such as the selection of appropriate sites to take water and soil samples) and seek equivalent learning experiences (perhaps providing the student with $3 \mathrm{G}$ phone technologies, videos, for use in selecting the sites, followed by discussion of the test results with other team members at base camp). This holistic approach to accessible learning has been accepted in a number of academic disciplines. For exam-

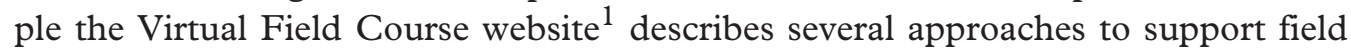
studies for students with disabilities.

\section{Accessible courses}

A holistic approach encourages a more bird's eye view of the learning experience encountered by disabled students. The learning path that the student chooses to follow should be accessible, while individual online components or learning objects may not. For example, consider a blind student who wishes to take a degree in biochemistry. When choosing a course the student should be advised on course modules that the student's disability may make it difficult for the student to pass 
(such as options that may require a student to peer through a microscope and describe what they see). Although such courses may not be possible for a blind student to take, the department could seek to provide accessible alternative course options, which would still allow the student to be awarded a degree.

\section{Adapting to individual, local, political and cultural factors}

A holistic approach, in our opinion, requires that individual needs and local cultural, political and social factors are taken into account. Since accessibility is primarily about people and not about technologies, the authors feel it is inappropriate to seek a universal solution. In seeking to provide accessible learning experiences it will be necessary to take into account the individual's specific needs, institutional factors, the subject discipline and the broader cultural and political factors. Instead of aiming to provide an e-learning resource that is accessible to everyone, we argue that there can be advantages in providing resources tailored for the student's particular needs.

\section{The holistic framework}

Our holistic framework for e-learning accessibility, which has been described elsewhere (Kelly et al., 2005c), is illustrated in Figure 1. We have represented our

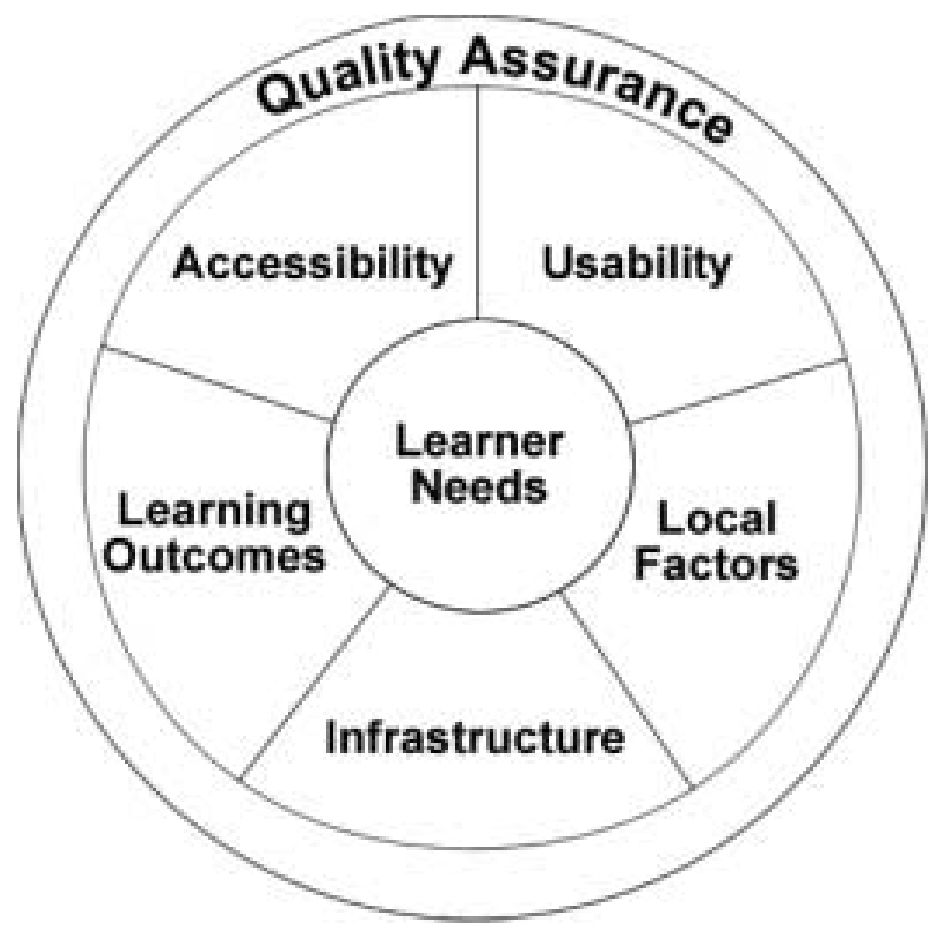

Figure 1. A holistic framework for e-learning accessibility 
framework as a circle in order to emphasise that the different parts are parts of a 'whole'. This is central to our argument that the approach to developing accessible e-learning needs to be holistic and consider more than the technical accessibility aspects of the e-learning. Therefore, rather than relying purely on the WAI guidelines, the framework incorporates the guidelines as part of a broader approach to the provision of accessible e-learning resources. There is a need to address the usability of e-learning resources, the pedagogic aims of the e-learning resources, infrastructural and resources issues and to provide solutions that are appropriate to the needs of the learner. This approach needs to be undertaken within a quality assurance framework in order to that documented policies are provided and systematic procedures for ensuring compliance with the policies are implemented.

\section{Discussion}

It could be argued that the holistic approach has limitations compared with the W3C WAI guidelines. The WAI guidelines can appear easier to implement as they provide a series of checklists. However, in our opinion, a checklist approach can in fact be counter-productive as it encourages developers to prioritise the objective areas on which testing tools can easily report. Another limitation of this approach may be its lack of universality, which is implicit in its inclusion of local (institutional) factors. This criticism may, in fact, be regarded in some quarters as a strength of the approach, as it does not seek to mandate a single global solution, but rather welcomes diversity and a learner-centric approach to e-learning.

While this work has been discussed and revised at length at various workshops and conferences, there is still a need to develop the framework and to provide examples of how it could be applied in a variety of circumstances, including differing learning environments, students with a variety of disabilities, use of various technologies and in a variety of different organisations.

\section{Offering solutions: a need for a holistic framework}

An article (Sitemorse, 2005) published by the accessibility auditing software company Sitemorse has generated heated debate over the relative merits of automated accessibility checking versus manual testing. The article describes the findings of an automated analysis carried out by Sitemorse across the websites of various disability organisations within the United Kingdom, including the RNIB, Royal National Institute for Deaf People (RNID) and the Disability Rights Commission, and so on. The arguments over the relevance of the findings clearly demonstrate a lack of consensus and illustrate the perceived difficulties that even national disability organisations find in complying with basic WAI WCAG guidelines. However, the article failed to provide a solution to these conflicts. The holistic framework does provide a resolution to this impasse because it enables those developers (e.g. disability organisations) who are targeting specific audiences to demonstrate how their material is accessible within the context of learner needs, usability and other local factors. 


\section{Applying the holistic approach to the e-learning development cycle}

In trying to provide pragmatic guidance to practitioners on how to apply the holistic approach to their own practices and contexts, what has emerged is a suggested framework for developers that could be applied at various points in an e-learning development process. What is illustrated in Table 1 is the result of discussions with colleagues in both the disability and e-learning areas of education. It is also a 'work in progress' in that we are not seeking to claim that this is the final answer, but we hope that it does help contribute to the discussion. The final caveat is that this is designed to be applicable to UK education institutions; we are not trying to create a model that will fit all areas of e-learning.

In using the framework in Table 1, it is suggested that developers document in some way the process as they work through it. This will be useful if challenged, but is also a means of reflecting on the process when undertaking further developments.

- Stage one: awareness. The developer is asked to consider specific issues relating to the development of e-learning material and to consider the needs of disabled students. For example, it is suggested that, if an online assessment is being created, the developer should be aware that there are issues related to how someone with a vision impairment would access it.

- Stage two: investigation. The developer, after becoming aware that there may be some issues with the resource, investigates what existing guidelines, 'standards' or practices are available that would support the resource under development in relation to inclusion. For example, it may be that the use of W3C guidelines is applicable in the creation of some content.

- Stage three: understanding. The developer must make a value judgement: are the practices identified in stage two valid for the resource under development? Furthermore, they must ensure that the application of the guidelines, 'standards' or practices

Table 1. Activities associated with applying the holistic framework to the e-learning development cycle

\begin{tabular}{|c|c|c|c|c|c|}
\hline $\begin{array}{l}\text { E-Learning } \\
\text { development } \\
\text { stage }\end{array}$ & $\begin{array}{l}\text { Stage one: } \\
\text { awareness }\end{array}$ & $\begin{array}{l}\text { Stage two: } \\
\text { investigation }\end{array}$ & $\begin{array}{l}\text { Stage three: } \\
\text { understanding }\end{array}$ & $\begin{array}{l}\text { Stage four: } \\
\text { implementation }\end{array}$ & $\begin{array}{l}\text { Stage five: } \\
\text { evaluation }\end{array}$ \\
\hline $\begin{array}{l}\text { Activities } \\
\text { undertaken } \\
\text { within this } \\
\text { stage }\end{array}$ & $\begin{array}{l}\text { Understanding } \\
\text { of resources } \\
\text { under } \\
\text { development } \\
\text { in relation to } \\
\text { inclusion }\end{array}$ & $\begin{array}{l}\text { Identification } \\
\text { of existing } \\
\text { established } \\
\text { practices }\end{array}$ & $\begin{array}{l}\text { Assessment of } \\
\text { applicability }\end{array}$ & $\begin{array}{l}\text { Identification of } \\
\text { alternative, } \\
\text { intervention or } \\
\text { adjustment }\end{array}$ & $\begin{array}{l}\text { Can the } \\
\text { student meet } \\
\text { the learning } \\
\text { outcomes? } \\
\text { Evaluation at } \\
\text { the macro } \\
\text { scale }\end{array}$ \\
\hline $\begin{array}{l}\text { Related } \\
\text { framework } \\
\text { component(s) }\end{array}$ & Learner needs & $\begin{array}{l}\text { Accessibility } \\
\text { Usability }\end{array}$ & $\begin{array}{l}\text { Infrastructure } \\
\text { Learning } \\
\text { outcomes }\end{array}$ & Local factors & $\begin{array}{l}\text { Quality } \\
\text { assurance }\end{array}$ \\
\hline
\end{tabular}


does not compromise the learning objective or outcome. For example, in an online assessment using images, an alt tag (describing the image) must not give away the answer.

- Stage four: implementation. This is probably the most important stage to document, after working through the processes and either developing a resource that is 'accessible' or one that may be inaccessible to some audiences, it may be necessary to identify other ways of achieving the learning objective. For example, a totally inaccessible online assessment, due to the material or system constraints, may be overcome by holding a viva voce for the student, or an inaccessible discussion group may result in a small group discussion with other students. Documenting these areas is important to ensure that the developer recognised the issues and began the process of identifying alternatives or adjustments.

- Stage five: evaluation. Evaluation of practice is key in ensuring that the needs of disabled students are met in learning environments. Here it is suggested that not only individual learning outcomes are evaluated, but a wider approach is taken. For example, where a project is funded to provide individual learning objects, it should be evaluated on the whole and not on each product.

\section{An example of using the five-stage process}

To illustrate the five stages and how they can be applied to practice, we offer an example of a vision-impaired learner accessing a computer-based assessment (via the Internet). In designing the assessment, the staff involved (lecturer/learning technologist) must understand the nature of the difficulty of accessing the material (stage one). This requires the individuals involved looking at and understanding the nature of the student's access requirement and what barriers there may be.

In stage two, the staff look at existing practices. With little written in the field of vision-impaired students accessing computer-based assessment, and the assessment being delivered via the Internet, it is likely that they will rely on web content accessibility guidelines (WAI, 1999), as an established maxim for the Web. However, in the case of this assessment a large amount of images are required.

Therefore, in stage three, the staff must decide whether the existing practice is applicable. Clearly the vision-impaired student would find difficulties in accessing the images in an assessment, and using an alternative description for the images part of the assessment may be negated. It may be assumed that the existing practice does not support the learning outcomes of the assessment or the student.

Stage four asks that an alternative is identified that does allow the student to access the learning and assessment. It may be that the student takes part in a discussion and their contribution assessed, or that they use tactile diagrams and feel a physical representation of the image.

Finally, the process should be evaluated in stage five. The evaluation should look at the needs of the student, whether the learning outcomes were met, whether the student was at an advantage or disadvantage over their non-disabled peers and whether the assessment was academically rigorous. 


\section{Conclusions}

This paper argues that although the W3C WAI guidelines for content accessibility are valuable, they should not be regarded as the only set of criteria that developers of e-learning resources need to consider. Not only is there a need to address a wider set of issues than those addressed in the WAI guidelines, there are also other factors that need to be addressed, some of which may conflict with WAI guidelines. In addition there is a need to place the learner at the centre of the development process. This approach focuses on the broad learning outcomes and recognises that inaccessible e-learning resources may be deployed, provided that disabled learners are still able to demonstrate the required learning outcomes in a way that does not disadvantage them or their non-disabled peers. The authors acknowledge that, in some quarters, these ideas made be regarded as controversial, especially in organisations that have defined e-learning accessibility policies solely using the WAI guidelines. It is also recognised that there is still an on-going debate to be held. The authors welcome comments and input to this debate.

\section{Acknowledgement}

This paper is adapted from 'Implementing A Holistic Approach To E-Learning Accessibility' (Kelly et al., 2005a), published in the ALT-C Conference 2005 Research Paper Proceedings.

\section{Notes}

1. The Virtual Field Course: http://www.geog.le.ac.uk/vfc/education/

\section{References}

Disability Rights Commission (2004) Formal investigation report: web accessibility. Available online at: http://www.drc-gb.org/publicationsandreports/report.asp (accessed 21 January 2005).

HMSO (2001) Special Educational Needs and Disability Act 2001, HMSO. Available online at: http://www.hmso.gov.uk/acts/acts2001/20010010.htm (accessed 18 May 2005).

Kelly, B., Guy, M. \& James, H. (2003a) Developing a quality culture for digital library programme, Informatica, 27(3). Available online at: http://www.ukoln.ac.uk/qa-focus/ documents/papers/eunis-2003/ (accessed 18 May 2005).

Kelly, B., Dunning, A., Guy, M. \& Phipps, L. (2003b) Ideology or pragmatism? Open standards and cultural heritage web sites, paper presented at ichim03 Proceedings, Paris (CDROM). Available online at: http://www.ukoln.ac.uk/qa-focus/documents/papers/ichim03/(accessed 10 March 2005).

Kelly, B., Sloan, D., Phipps, L., Petrie, H. \& Hamilton, F. (2005a) Forcing standardization or accommodating diversity? A framework for applying the WCAG in the real world, Proceedings of the 2005 International Cross-Disciplinary Workshop on Web Accessibility (W4A). Available online at: http://www.ukoln.ac.uk/web-focus/papers/w4a-2005/ (accessed 18 May 2005).

Kelly, B., Phipps, L. \& Howell, C. (2005b) Implementing a holistic approach to e-learning accessibility, in: J. Cook \& D. Whitelock (Eds) Exploring the frontiers of e-learning: borders, outposts and migration; ALT-C 2005 12th International Conference Research Proceedings (Oxford, ALT). 
Kelly, B., Phipps, L. \& Swift, E. (2005c) Developing a holistic approach for e-learning accessibility, Canadian Fournal of Learning and Technology, 30(3). Available online at: http:// www.ukoln.ac.uk/qa-focus/papers/cjtl-2004/ (accessed 18 May 2005).

RNIB (undated) Flash web access centre. Available online at: http://www.rnib.org.uk/xpedio/groups/ public/documents/publicwebsite/public_macromediaflash.hcsp (accessed 18 May 2005).

Sitemorse (2005) Confusion reigns over website accessibility compliance. Available online at: http:// www.business2www.com/news.html?id=1217547344 (accessed 18 May 2005).

Sloan, M. (2002) E-learning and legislation. Available online at: http://www.techdis.ac.uk/resources/ msloan02.html (accessed 18 May 2005).

WAI (1999) Web content accessibility guidelines 1.0, W3C recommendation 5 May 1999. Available online at: http://www.w3.org/TR/WCAG10/ (accessed 18 May 2005).

WAI (2004) Web content accessibility guidelines 2.0. W3C working draft 19 November 2004. Available online at: http://www.w3.org/TR/WCAG20/ (accessed 18 May 2005).

Willder, B. (2002) Disability legislation: implications for learning technologists in the UK, in: L. Phipps, A. Sutherland \& J. Seale (Eds) Access all areas: disability, technology and learning (ALT/ JISC/TechDis), 6-9.

Witt, N. A. J. \& McDermott, A. P. (2002) Achieving SENDA-compliance for web sites in further and higher education: an art or a science?, in: L. Phipps, A. Sutherland \& J. Seale (Eds) Access all areas: disability, technology and learning (ALT/JISC/TechDis), 42-49. 